\title{
EFFECTS OF SPIRAL LINE FOR PICK ARRANGEMENT ON BOOM TYPE ROADHEADER CUTTING LOAD
}

\author{
Li, X. Y.; Lv, Y. G.; Jiang, S. B. \& Zeng, Q. L. \\ College of Mechanical and Electronic Engineering, Shandong University of Science and Technology, \\ Qingdao 266590, China \\ E-Mail: lixueyi07@tsinghua.org.cn, yongganglv406@163.com, jiangshoubo@126.com,
} qlzeng@163.com

\begin{abstract}
The effects of the spiral line for pick arrangement on the cutting load of a boom type roadheader's cutting head were investigated. For this purpose, cutting heads with equal and unequal pitch angle and various numbers of spiral lines were designed for the same cutting head body. The cutting head with unequal pitch angle of spiral lines was specifically designed to avoid tool-holder overlap at the top section without adjustments and reduce the manufacturing difficulties. The cutting process of different cutting heads were simulated by finite element method using ANSYS/LS-DYNA and the time history curve of the traversing force, vertical force, axial force, and resultant force on the cutting head were obtained. The results indicate that the load stability of the cutting head with unequal pitch angle was worse than the equal pitch angle cutting head. For cutting heads with various numbers of spiral lines, the head with 3 spiral lines shows the best performance, considering the force values and fluctuations of the cutting head. The analysis provides a reliable basis for optimization of the design of boom type roadheader cutting heads.

(Received, processed and accepted by the Chinese Representative Office.)
\end{abstract}

Key Words: Cutting Head, Pick Arrangement, Spiral Line, Cutting Head Design, Cutting Load, Boom Type Roadheader

\section{INTRODUCTION}

The cutting head is an important part of a roadheader and the design of it is one of the most important parameters affecting the performance and work efficiency of boom-type tunnelling machines $[1,2]$. The main fundamental factors involved in head design are the size of head body, number and size of picks, spiral line for pick arrangement, number of spiral lines, number of tools per line, circumferential pick spacing, and pick rake angle. The longitudinal cutting head body usually combines with the cylinder, circular cone, and sphere, so the spiral lines for pick arrangement include cylindrical helix, conical helix, and spherical helix. Reasonable cutting head design can reduce the wear rate of the pick and the vibration of the whole machine, which improves cutting efficiency [3-6].

Many scholars have studied the pick arrangement of roadheader cutting head in the last three decades. Goktan [7] analysed the effect of cutter pick rake angle on the failure pattern of high-strength rocks. Eyyuboglu and Bolukbasi [8] and Hekimoglu and Fowell [9] researched the effects of circumferential pick spacing on boom type roadheader cutting head performance by theoretical analysis and practical testing. Hekimoglu et al. $[10,11]$ studied radial line for cutting head pick lacing arrangements and the effect of the angle of wrap on cutting performance of drum shearers and continuous miners. Yang and Zhou [12] studied pick arrangement on cutting head of a roadheader and put forward a new method of equality intercept and circle-angle for pick arrangement. Li et al. [13] compared the performance of two cutting heads with different kinds of pick arrangement and found that the cutting performance of pick arrangement based on an equal pitch angle spiral line was good because of its reasonable pick cut, its uniform cutting pattern and the small fluctuation of its load. Wang and Zhang [14] studied spiral design of longitudinal roadheader cutting head and found 
a good arrangement plan which combined with an equal helix angle conical spiral and spherical helix. Yang et al. [15] researched design parameters of cutting head of a longitudinal roadheader and discussed the distribution of pick arrangement. Zhang [16] analysed the influence of pick array circumferential angle on cutting performance of longitudinal cutting heads by theoretical analysis and simulation. However, the spiral line for pick arrangement of a cutting head was seldom considered. In particular, the effects of pitch angle and number of spiral lines on boom type roadheader cutting head have not been researched clearly.

With the continuous development of computer and simulation technology, computer aided design (CAD) and computer aided engineering (CAE) techniques are widely used in cutting head design and analysis, and the design level of cutting head has improved rapidly [17]. Tiryaki et al. [18] developed a new computer program for cutting head design of roadheaders and drum shearers. Rojek et al. [19] and Su and Akcin [20] studied numerical simulation of rock cutting using the discrete element method and compared the results with experimental and theoretical studies. Therefore, this paper is aimed at the effects of spiral line for pick arrangement on boom type roadheader cutting loads. For this purpose, the cutting process of the cutting head was studied by numerical simulation using ANSYS/LS-DYNA and the comparison of unequal pitch angle and equal pitch angle for spiral line, and the various numbers of spiral lines were investigated.

\section{DESIGN OF SPIRAL LINE AND CUTTING HEAD}

In order to get the best cutting effect, the pick was arranged on the cutting head body along the spiral line. The longitudinal cutting head body is usually combined with cylinder, circular cone, and sphere, so the spiral lines for pick arrangement include cylindrical helix, conical helix, and spherical helix.

\subsection{Parametric equation of spiral line}

Traditionally, we use the equation of the spiral line for the equal pitch angle pick arrangement as follows:

- Cylindrical helix:

$$
\left\{\begin{array}{l}
x=r_{1} \cos \omega t \\
y=r_{1} \sin \omega t \\
z=\lambda \omega t / 2 \pi
\end{array}\right.
$$

- Conical helix:

$$
\left\{\begin{array}{c}
x=(\lambda \omega t / 2 \pi) \tan (\varphi / 2) \cos \omega t \\
y=(\lambda \omega t / 2 \pi) \tan (\varphi / 2) \sin \omega t \\
z=\lambda \omega t / 2 \pi
\end{array}\right.
$$

- Spherical helix:

$$
\left\{\begin{array}{c}
x=r_{2} \cos \left(\lambda \omega t / 2 \pi r_{2}\right) \cos \omega t \\
y=r_{2} \cos \left(\lambda \omega t / 2 \pi r_{2}\right) \sin \omega t \\
z=r_{2} \sin \left(\lambda \omega t / 2 \pi r_{2}\right)
\end{array}\right.
$$

where: $x, y$ and $z$ are the Cartesian coordinates of the spiral line, $r_{1}$ is the cylindrical radius, $r_{2}$ is the spherical radius, $\omega$ is the rotary angular velocity of generatrix, $t$ is the time for rotary, $\lambda$ is the helical pitch, $\varphi$ is the cone apex angle.

However, these equations can't express the pitch angle, which is the angle between the tangent of the spiral line and the tangent of the circular cross-section through a point on the spiral line. Yang et al. [21] and Fu et al. [22] put forward the variable pitch angle concept 
which can be used to describe the spiral lines with pitch angle. The equations are shown as follows [23]:

- Cylindrical helix:

$$
\left\{\begin{array}{c}
x=r_{1} \cos \theta \\
y=r_{1} \sin \theta \\
z=r_{1} \theta \tan \varepsilon
\end{array}\right.
$$

- Conical helix:

$$
\left\{\begin{array}{l}
x=\rho \cos \theta \exp ^{-\theta \sin \psi \tan \varepsilon} \\
y=\rho \sin \theta \exp ^{-\theta \sin \psi \tan \varepsilon} \\
z=\rho \cot \psi \exp ^{-\theta \sin \psi \tan \varepsilon}
\end{array}\right.
$$

- Spherical helix:

$$
\left\{\begin{array}{c}
x=2 r_{2} \cos \theta A \exp ^{-\theta \tan \varepsilon} /\left(1+A^{2} \exp ^{-2 \theta \tan \varepsilon}\right) \\
y=2 r_{2} \sin \theta A \exp ^{-\theta \tan \varepsilon} /\left(1+A^{2} \exp ^{-2 \theta \tan \varepsilon}\right) \\
z=r_{2}\left(1-A^{2} \exp ^{-2 \theta \tan \varepsilon}\right) /\left(1+A^{2} \exp ^{-2 \theta \tan \varepsilon}\right)
\end{array}\right.
$$

where: $\theta$ is the angle of circumference corresponding point on the spiral lines, $\varepsilon$ is the pitch angle of the spiral lines, $\rho$ is the conical large radius, $\psi$ is the half cone apex angle, $A$ is a constant. The others are the same as Eqs. (1) to (3). The pitch angle $\varepsilon$ changes continuously during the transition region between different characteristics.

We can see $\theta$ as the independent variable, and the pitch angle $\varepsilon$ changes with $\theta$ according to a certain rule, the variable pitch angle spiral line can be obtained.

\subsection{Design of pitch angle and number of spiral line}

In order to compare the effects of equal and unequal pitch angle and number of spiral lines on cutting load, the cutting heads with equal and unequal pitch angles and various numbers of spiral lines were designed for the same cutting head body. We researched the effects of pitch angle using the parametric equation of the spiral line shown in Eqs. (4) to (6) and set the pitch angle parameter as shown in Fig. 1 with the same number of spiral lines. In order to improve the efficiency of analysis, we first studied the effects of equal and unequal pitch angle on cutting load, and then built the various numbers of spiral lines with better pitch angles. The number of spiral lines was defined as 2,3 and 4 .

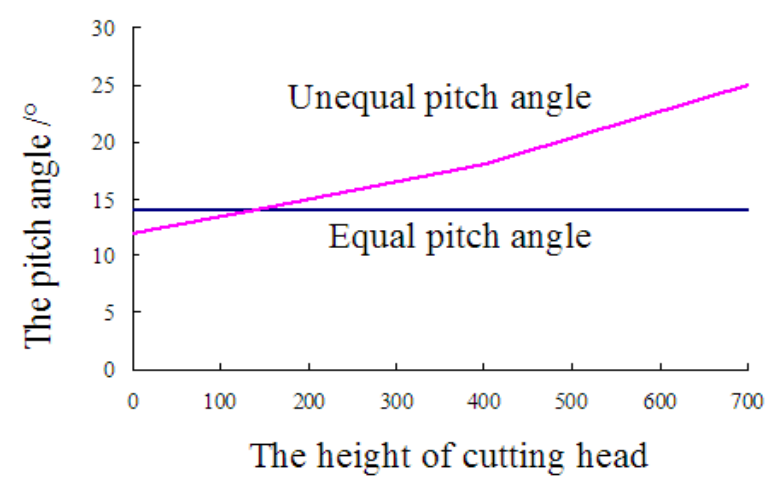

Figure 1: The pitch angle of cutting head.

\subsection{Design and modelling of cutting head}

The overall dimensions of the cutting head are shown in Fig. 2. In order to make the research comparable, for different cutting we set the line spacing between picks as $30 \mathrm{~mm}$, with one tool per line. 


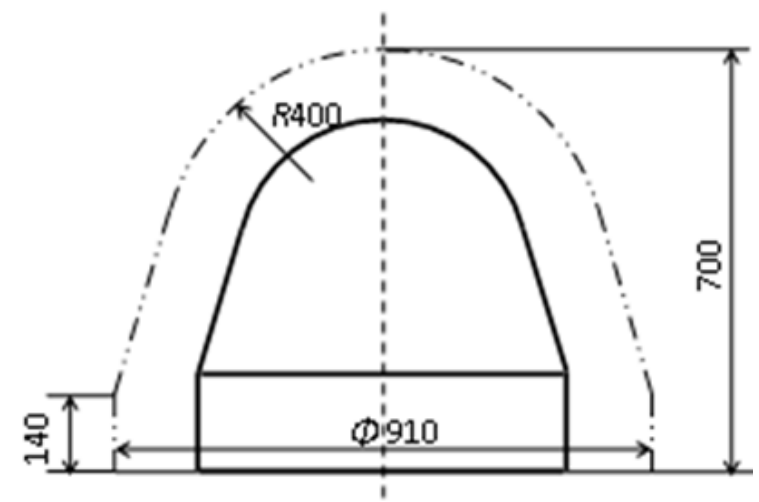

Figure 2: The overall dimensions of the cutting head $(\mathrm{mm})$.

The cutting picks and tool-holders used were also the same for different cutting heads: ten picks can be arranged per spiral line, and the number of spiral lines was defined as 3 for the research of the effects of equal and unequal pitch angle on cutting load. The setting angles of picks were defined as $48^{\circ}$ and the inclination angles were all defined as $8^{\circ}$ as shown in Fig. 3 . The pick arrangements of the cutting heads are shown in Fig. 4. The first cutting head was designed with unequal pitch angle to avoid tool-holder overlap without adjustments. The second cutting head was designed at $14^{\circ}$ equal pitch angle of spiral line, and adjustments of picks were made at the top of the cutting head to avoid tool-holder overlap. The solid models of cutting head are shown in Fig. 5 and the number of picks is considered to be constant and equal to 30 picks in all simulations.

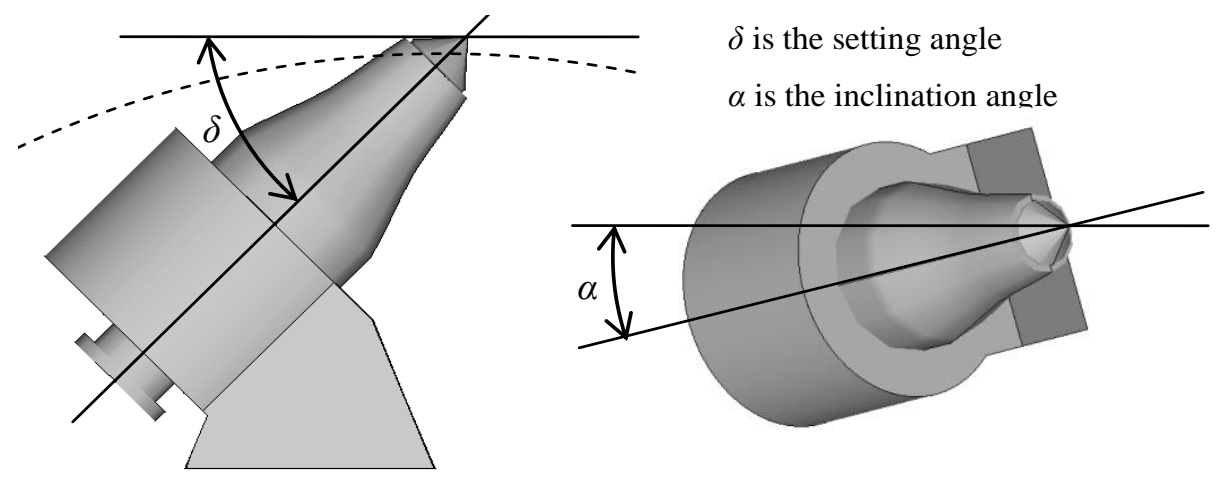

Figure 3: Setting angle and inclination angle of picks.

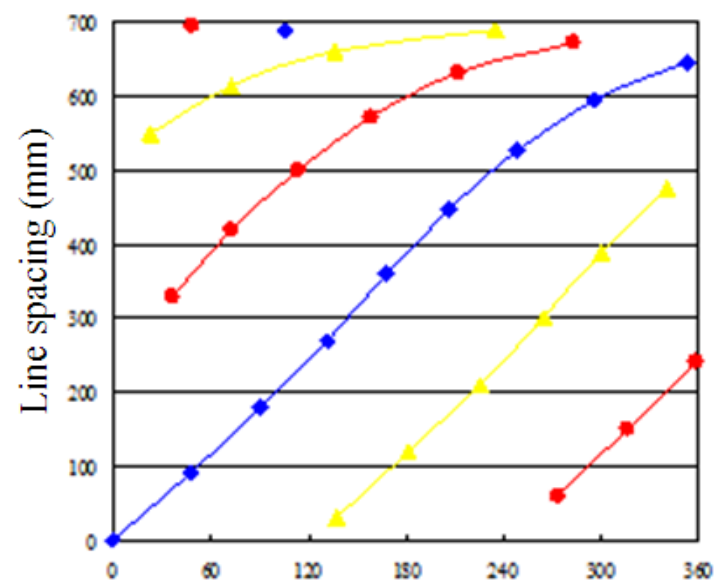

Circumferential pick spacing $\left(^{\circ}\right)$ Unequal

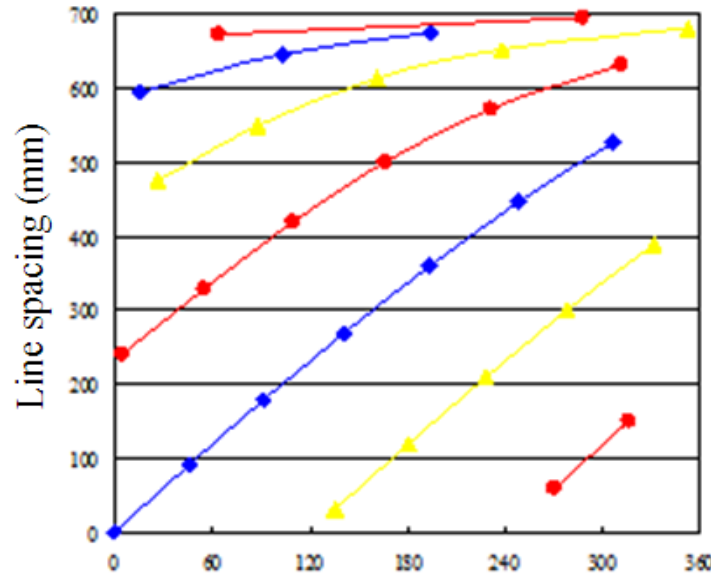

Circumferential pick spacing $\left(^{\circ}\right)$ Equal

Figure 4: The pick arrangements of cutting heads with different pitch angle. 


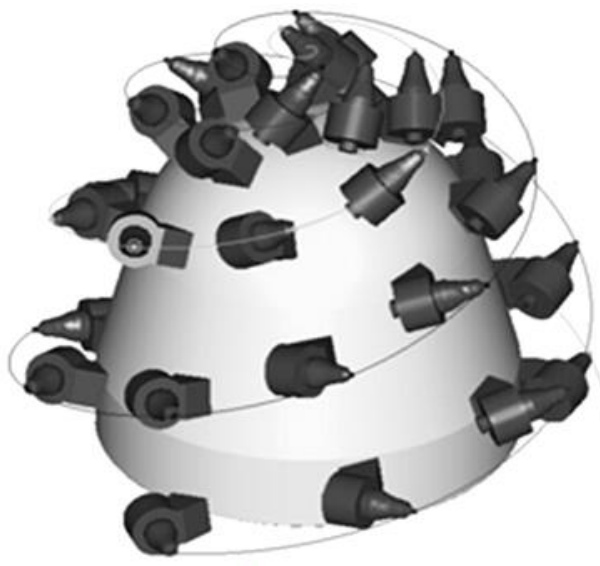

Unequal

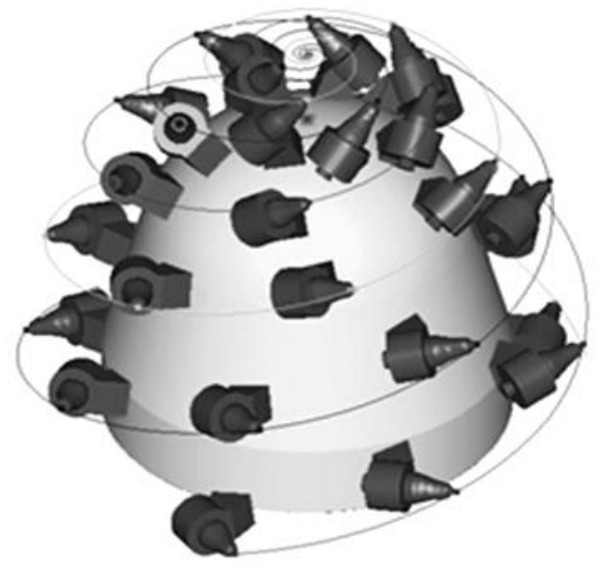

Equal

Figure 5: The solid models of cutting heads with different pitch angle.

\section{CUTTING LOAD CALCULATION OF CUTTING HEAD}

Cutting load is a main factor which directly reflects the work conditions of the machine and the cutting performance. Many scholars have studied the methods to calculate the cutting load of a cutting head [24-27]. However, no accepted and unified calculation method has been put forward. The loads on the cutting head are dynamic and nonlinear due to the nonlinear contact, nonlinear materials, and complex arrangements of cutting picks. Therefore, the theoretical calculation method can't describe the complex process of coal and rock cutting accurately and comprehensively. So we will try to calculate the cutting load by the finite element simulation method in this paper.

In order to analyse the dynamic cutting load on the cutting head, finite element simulation by ANSYS/LS-DYNA was used, which is a general, explicit, dynamic analysis program widely used in the engineering field. The simulation process mainly includes the establishment of a 3D (three dimensional) model, selecting element type, defining the material parameter, finite element modelling, defining the contact, loading, setting the constraints, and solving the job.

In this analysis, we selected a SOLID 164 unit and defined a rigid material for the cutting head and No. 193 material (MAT_DRUCKER_PRAGER) for coal and rock. The material parameters are shown in Table I. The contact type between them was set for eroding surface to surface (ESTS), rotation velocity of $36 \mathrm{r} / \mathrm{min}$ and horizontal swing velocity of $1.5 \mathrm{~m} / \mathrm{min}$ were applied to the cutting head. Non-reflecting boundary conditions were added to the surfaces of coal and rock without cutting in the simulation system and the degrees of freedom of other directions were limited. The output contact surface reaction keyword "RCFORC" was added for the force output of the cutting head [28].

Table I: Material parameters.

\begin{tabular}{|c|c|c|c|c|c|c|c|}
\hline & $\begin{array}{c}\text { Mass } \\
\text { density } \\
\left(\mathrm{g} / \mathrm{mm}^{2}\right)\end{array}$ & $\begin{array}{l}\text { Poisson's } \\
\text { ratio }\end{array}$ & $\begin{array}{c}\text { Elastic } \\
\text { shear } \\
\text { modulus } \\
(\mathrm{MPa})\end{array}$ & $\begin{array}{c}\text { Failure } \\
\text { surface } \\
\text { shape } \\
\text { parameter }\end{array}$ & $\begin{array}{l}\text { Angle of } \\
\text { friction } \\
\quad(\mathrm{rad})\end{array}$ & $\begin{array}{c}\text { Cohesion } \\
\text { value } \\
(\mathrm{MPa})\end{array}$ & $\begin{array}{c}\text { Dilation } \\
\text { angle }\end{array}$ \\
\hline Coal-rock & $1.5 \mathrm{e}-3$ & 0.3 & 1400 & 1 & 0.45 & 0.766 & 0 \\
\hline Cutting head & $7.8 e-3$ & 0.3 & $2.7 e+5$ & & & & \\
\hline
\end{tabular}

The finite element simulation model of cutting head for cutting load calculation is shown in Fig. 6. With this model, we can obtain the time history curve of the traversing force, vertical force, axial force, and resultant force on the cutting head. 


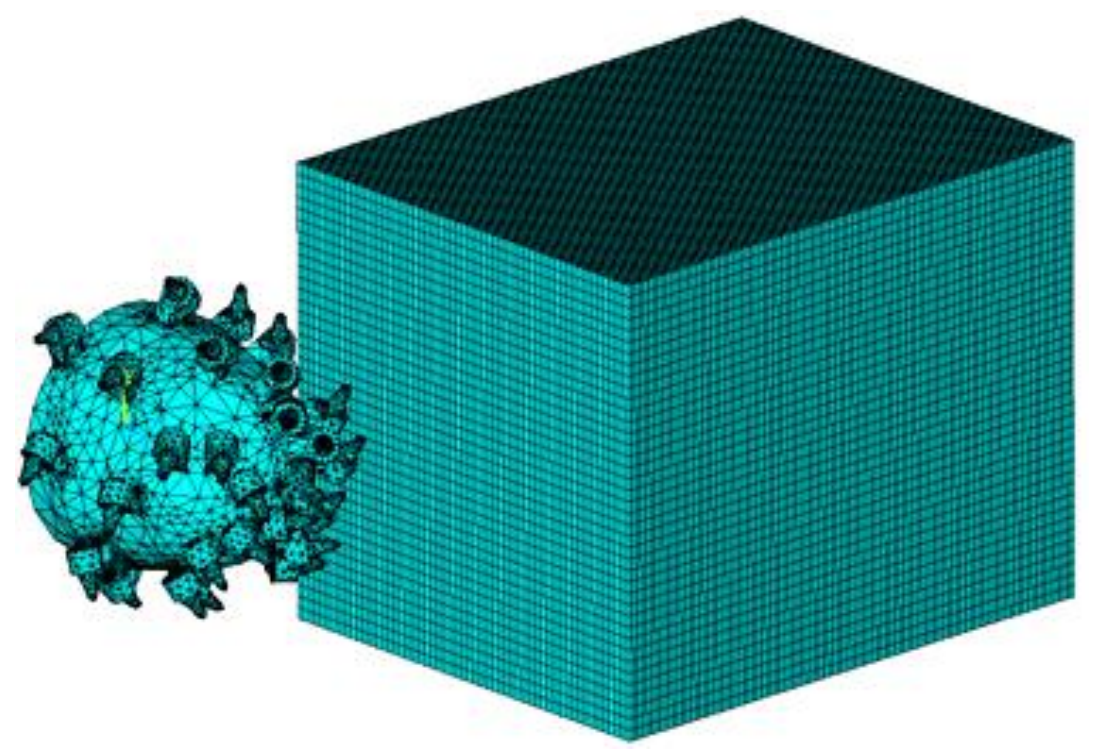

Figure 6: The finite element simulation model of cutting head.

\section{CUTTING LOAD COMPARISON OF THE CUTTING HEADS WITH EQUAL AND UNEQUAL PITCH ANGLE}

In order to analyse the effects of pitch angle on cutting load of the cutting head, the cutting process was simulated with different models. The time history curves of the force on the cutting head with different pitch angles are shown in Figs. 7 and 8.
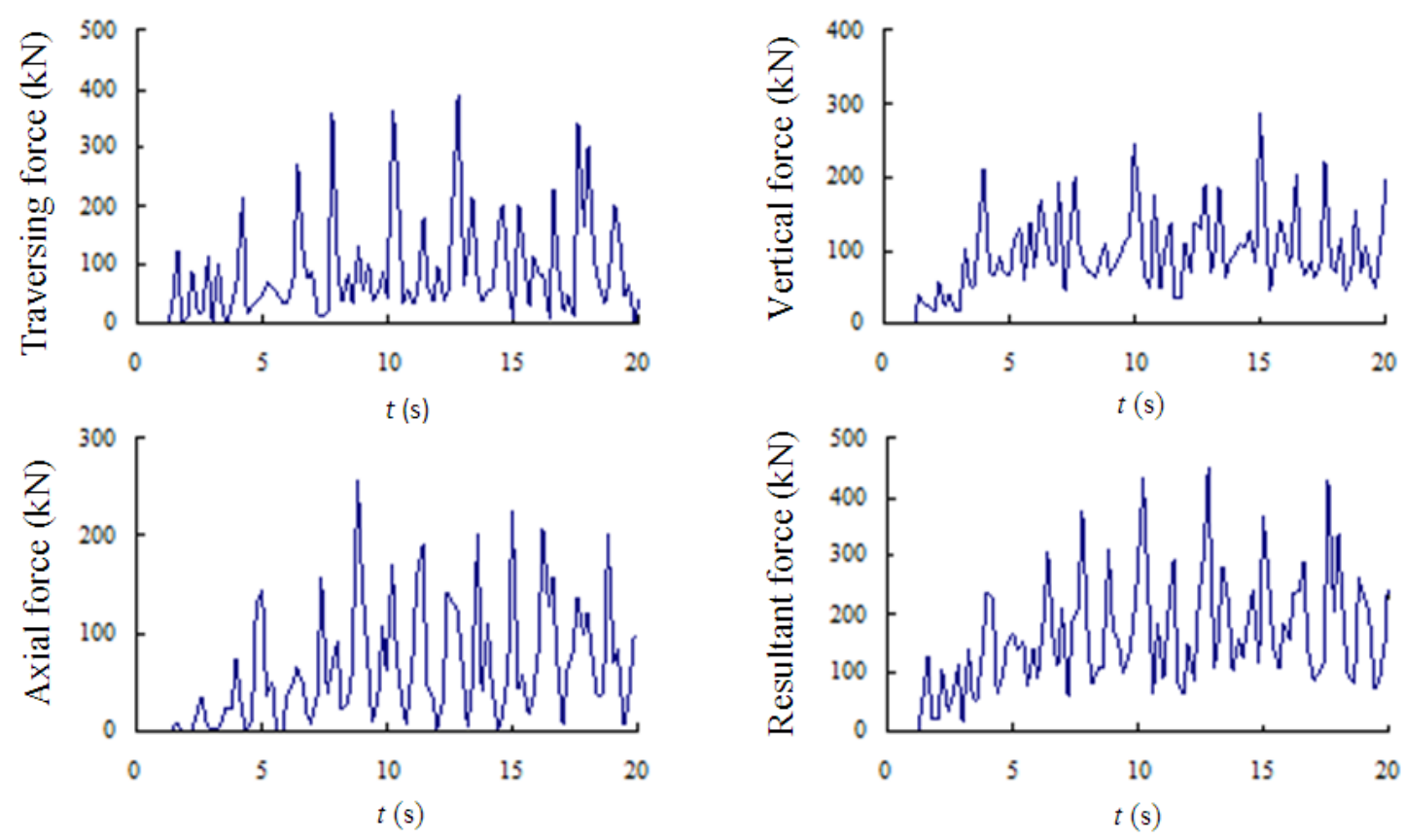

Figure 7: Time history curve of the force on cutting head with unequal pitch angle.

It can be seen from Fig. 8 that all the forces change with time and show irregular fluctuations. The force fluctuations of the cutting heads with unequal pitch angle are larger than the equal pitch angle cutting heads. In order to see the force variation imposed on the cutting heads, the statistic of the forces was taken and the values are shown in Table II. 

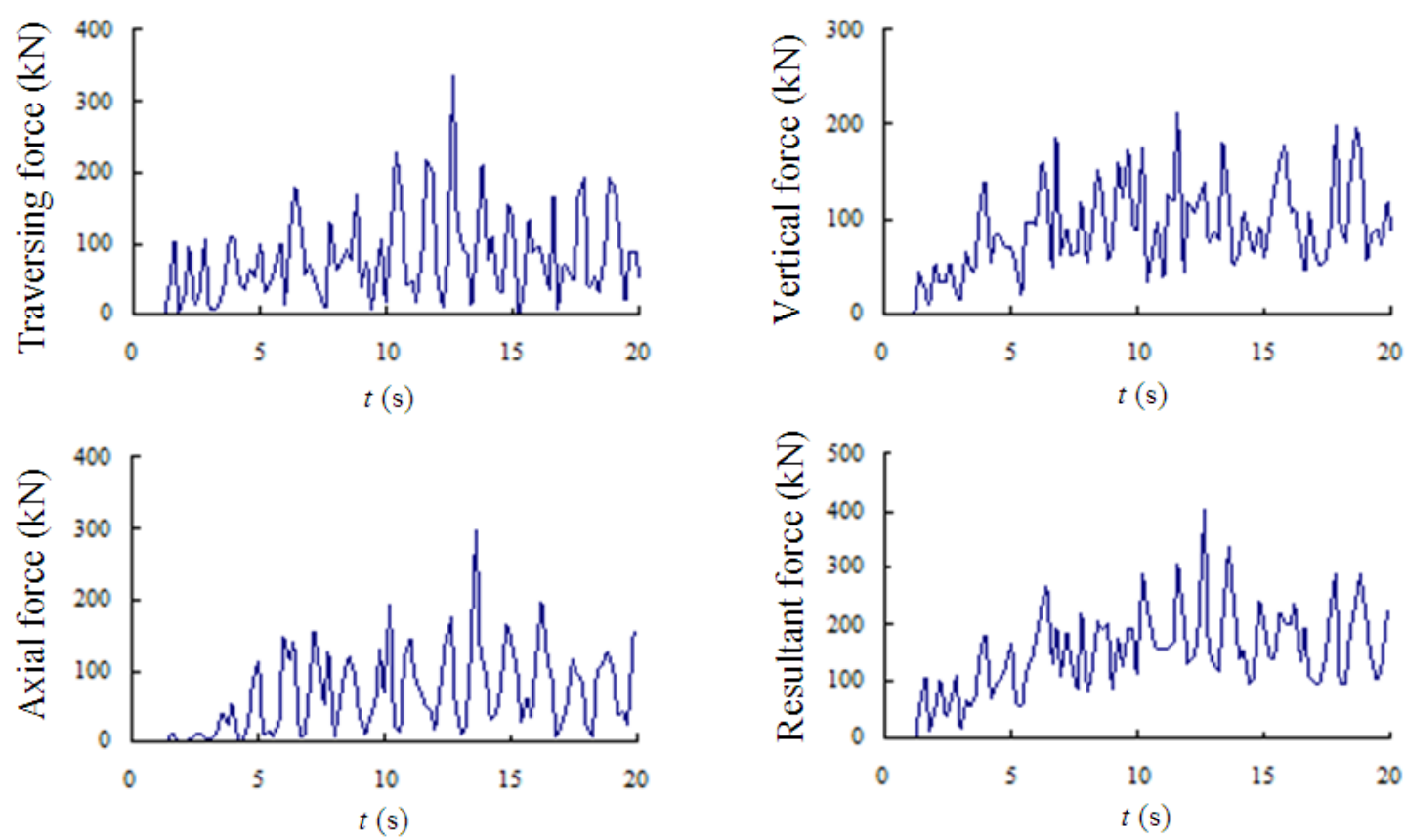

Figure 8: Time history curve of the force on cutting head with equal pitch angle.

Table II: Statistics of force on cutting head with different pitch angle.

\begin{tabular}{|c|l|c|c|c|c|}
\hline Type & \multicolumn{1}{|c|}{ Statistic } & $\begin{array}{c}\text { Traversing } \\
\text { force }(\mathrm{kN})\end{array}$ & $\begin{array}{c}\text { Vertical } \\
\text { force }(\mathrm{kN})\end{array}$ & $\begin{array}{c}\text { Axial force } \\
(\mathrm{kN})\end{array}$ & $\begin{array}{c}\text { Resultant } \\
\text { force }(\mathrm{kN})\end{array}$ \\
\hline \multirow{3}{*}{ Unequal } & Maximum & 389.87 & 287.38 & 256.66 & 450.86 \\
& Mean & 90.12 & 96.16 & 65.00 & 164.31 \\
& Standard deviation & 88.57 & 54.70 & 62.16 & 96.12 \\
& Variation coefficient & 0.98 & 0.57 & 0.96 & 0.58 \\
\hline \multirow{5}{*}{ Equal } & Maximum & 333.50 & 212.30 & 294.62 & 401.11 \\
& Mean & 79.87 & 91.13 & 67.82 & 153.47 \\
& Standard deviation & 62.71 & 47.18 & 60.11 & 73.87 \\
& Variation coefficient & 0.79 & 0.52 & 0.89 & 0.48 \\
\hline
\end{tabular}

The statistical results indicate that the mean values of the traversing force, vertical force, and resultant force on the cutting head with unequal pitch angle increased by $12.83 \%, 5.52 \%$, and $7.06 \%$ respectively. When compared with equal pitch angle heads during the swing cutting process, the mean axial force values were about the same. There were significant increases in the variation coefficient of all the forces of the head with unequal pitch angle, which indicates that, the larger force fluctuations will lead to more serious vibrations on the cutting head, and in turn, decrease the life of cutting picks and whole cutting head. Therefore, although the cutting head with unequal pitch angle can avoid tool-holder overlap at the top of the cutting head and can reduce the manufacturing difficulty, the load stability of this cutting head is worse than an equal pitch angle cutting head.

\section{CUTTING LOAD COMPARISON OF THE CUTTING HEADS WITH VARIOUS NUMBERS OF SPIRAL LINES}

In order to compare the effects of various numbers of spiral lines on the cutting load, the cutting heads with 2, 3 and 4 spiral lines were designed. In the previous section we discovered 
that a cutting head with equal pitch angle had better performance, so we built the heads with various numbers of spiral lines using the equal pitch angle model. The cutting process of the cutting head with 3 spiral lines had been simulated previously, so we built another two cutting heads with 2 and 4 spiral lines for the simulation. The solid models of cutting heads are shown in Fig. 9.

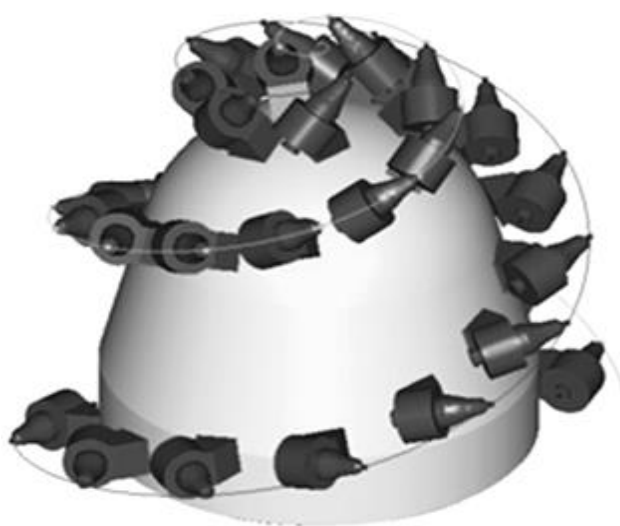

2 spiral lines

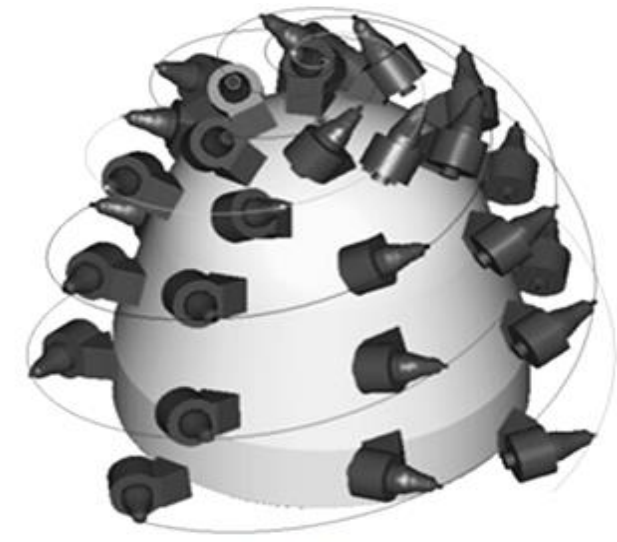

4 spiral lines

Figure 9: The solid models of cutting head with various numbers of spiral lines.

The cutting process was simulated with different numbers of spiral lines. The time history curves of the force on the cutting heads with 2 and 4 spiral lines are shown in Figs. 10 and 11, and the calculated cutting forces are shown in Table III.
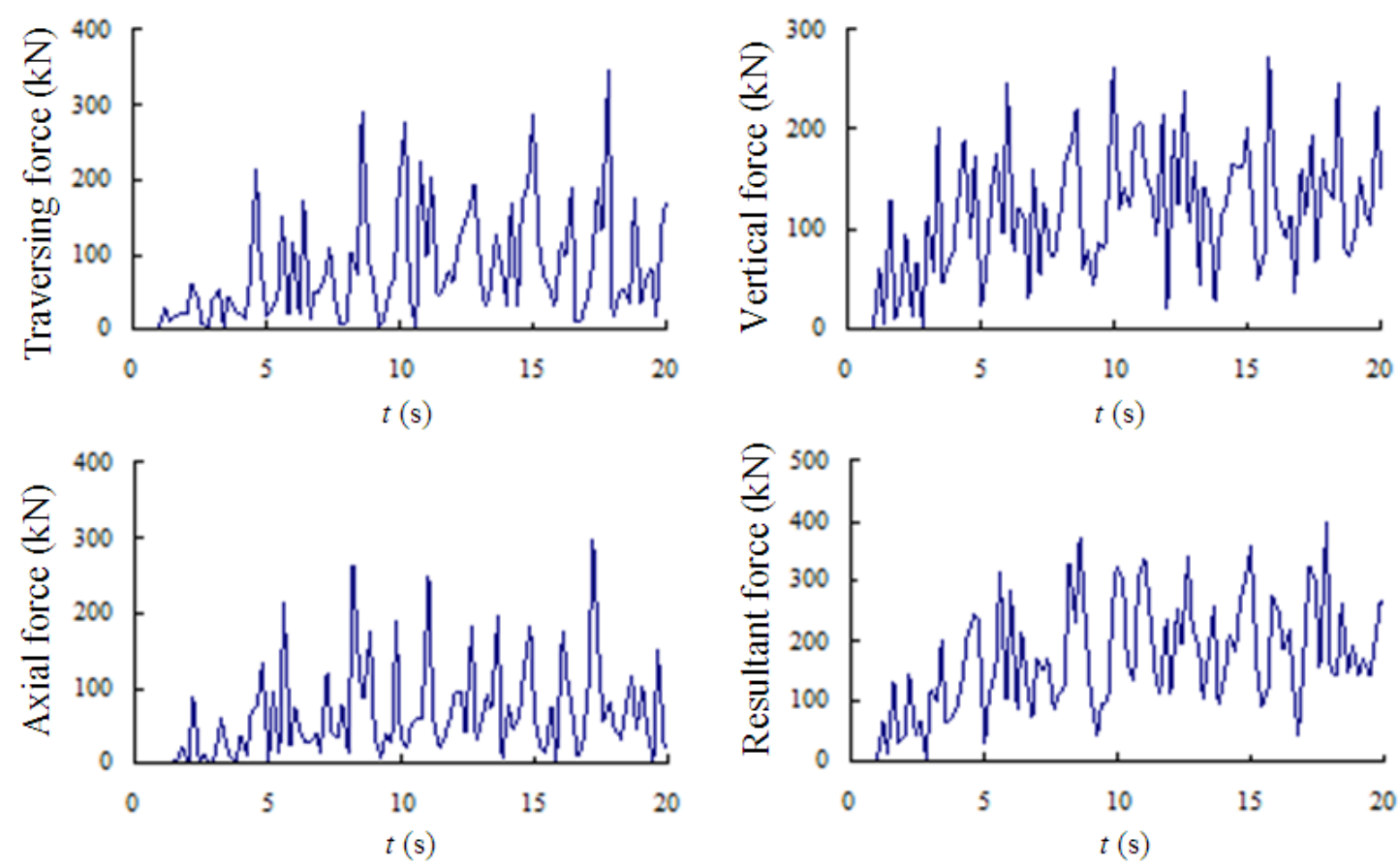

Figure 10: Time history curve of the force on cutting head with 2 spiral lines.

From the time history curves and calculated results of force on the cutting head with various numbers of spiral lines, we can see that compared with the cutting head with 3 spiral lines, the mean values of traversing force, vertical force, and resultant force on the cutting head with 2 spiral lines increased by $3.34 \%, 30.29 \%$, and $13.83 \%$ respectively. The variation coefficients of all the forces on the cutting head with 2 spiral lines were larger than on the cutting head with 3 spiral lines. The results also indicated that although the mean force values 
on the cutting head with 4 spiral lines were about the same as that on the cutting head with 3 spiral lines, there are significant increases in the variation coefficients of the traversing force and resultant force on the cutting head with 4 spiral lines. Additionally, cutting heads with greater numbers of spiral lines are more difficult to manufacture. Therefore, the cutting head with 3 spiral lines is the optimum choice for boom type roadheaders.
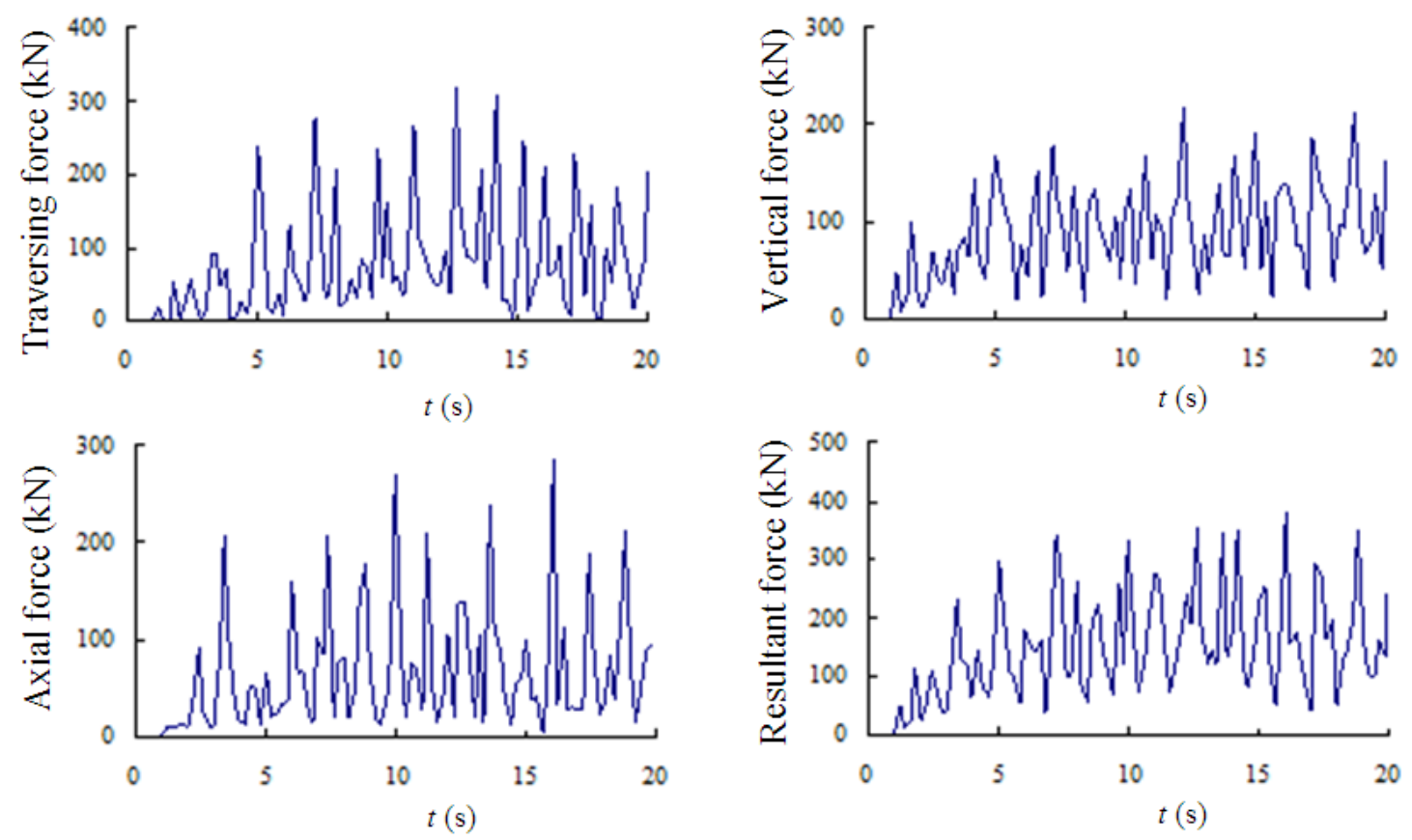

Figure 11: Time history curve of the force on cutting head with 4 spiral lines.

Table III: Statistics of force on cutting head with various numbers of spiral lines.

\begin{tabular}{|c|c|c|c|c|c|}
\hline Type & Statistic & $\begin{array}{l}\text { Traversing } \\
\text { force }(\mathrm{kN})\end{array}$ & $\begin{array}{c}\text { Vertical } \\
\text { force }(k N)\end{array}$ & $\begin{array}{c}\text { Axial force } \\
(\mathrm{kN})\end{array}$ & $\begin{array}{l}\text { Resultant } \\
\text { force }(\mathrm{kN})\end{array}$ \\
\hline \multirow{4}{*}{$\begin{array}{c}2 \\
\text { spiral } \\
\text { lines }\end{array}$} & Maximum & 345.59 & 274.23 & 297.86 & 393.61 \\
\hline & Mean & 82.54 & 118.73 & 65.98 & 174.70 \\
\hline & Standard deviation & 75.12 & 62.97 & 63.38 & 91.18 \\
\hline & Variation coefficient & 0.91 & 0.53 & 0.96 & 0.52 \\
\hline \multirow{4}{*}{$\begin{array}{c}3 \\
\text { spiral } \\
\text { lines }\end{array}$} & Maximum & 333.50 & 212.30 & 294.62 & 401.11 \\
\hline & Mean & 79.87 & 91.13 & 67.82 & 153.47 \\
\hline & Standard deviation & 62.71 & 47.18 & 60.11 & 73.87 \\
\hline & Variation coefficient & 0.79 & 0.52 & 0.89 & 0.48 \\
\hline \multirow{4}{*}{$\begin{array}{c}4 \\
\text { spiral } \\
\text { lines }\end{array}$} & Maximum & 318.11 & 217.68 & 285.01 & 382.20 \\
\hline & Mean & 80.18 & 91.09 & 70.70 & 155.42 \\
\hline & Standard deviation & 76.67 & 48.74 & 63.98 & 88.70 \\
\hline & Variation coefficient & 0.96 & 0.54 & 0.90 & 0.57 \\
\hline
\end{tabular}

\section{CONCLUSION}

In order to compare the effects of spiral line for pick arrangement on boom type roadheader cutting loads, cutting heads with equal and unequal pitch angles and various numbers of spiral lines were designed for the same cutting head body, and the cutting process of the cutting 
head was studied by numerical simulation using ANSYS/LS-DYNA. The unequal pitch angle and equal pitch angle for spiral line were compared along with the effect of changing the number of spiral lines. The following conclusions can be drawn from the results obtained in this study.

(1) The mean values of the traversing force, vertical force, and resultant force on the cutting head with unequal pitch angle increased $12.83 \%, 5.52 \%$, and $7.06 \%$ respectively compared with the cutting head with equal pitch angle. There were significant increases in the variation coefficient of all the forces on the cutting head with unequal pitch angle. The load stability of the cutting head with equal pitch angle was better than the unequal pitch angle cutting head.

(2) The mean values of the traversing force, vertical force, and resultant force on the cutting head with 2 spiral lines increased $3.34 \%, 30.29 \%$, and $13.83 \%$ respectively compared with the cutting head with 3 spiral lines. The mean force values of the head with 4 spiral lines were about the same as that on the cutting head with 3 spiral lines. However, there were significant increases in the variation coefficient of the traversing force and resultant force on the cutting head with 4 spiral lines. Therefore, the cutting head with 3 spiral lines is the best choice for the design of a boom type roadheader.

\section{ACKNOWLEDGEMENT}

This work was supported by the National Natural Science Foundation of China (Grant No. 51375282), the Special Funds for Cultivation of Taishan Scholars, the Shandong Provincial Natural Science Foundation of China (Grant No. ZR2015EM017 \& ZR2014EEM021), the Science and Technology Development Program of Shandong Province (Grant No. 2014GGX103043), and the Innovation Foundation for Graduate Students of Shandong University of Science and Technology (Grant No. YC150211).

\section{REFERENCES}

[1] Ergin, H.; Acaroglu, O. (2007). The effect of machine design parameters on the stability of a roadheader, Tunnelling and Underground Space Technology, Vol. 22, No. 1, 80-89, doi:10.1016/j.tust.2006.04.003

[2] Eyyuboglu, E. M. (2003). Cutting head design of boom type roadheaders, İstanbul Üniversitesi Mühendislik Fakültesi Yerbilimleri Dergisi, Vol. 16, No. 2, 43-50 (in Turkish)

[3] Acaroglu, O.; Ergin, H. (2005). The effect of cutting head shapes on roadheader stability, Mining Technology, Vol. 114, No. 3, 140-146, doi:10.1179/037178405X54015

[4] Hurt, K. G.; MacAndrew, K. M. (1985). Cutting efficiency and life of rock-cutting picks, Mining Science and Technology, Vol. 2, No. 2, 139-151, doi:10.1016/S0167-9031(85)90357-3

[5] Pickering, R. G. B.; Ebner, B. (2002). Hard rock cutting and the development of a continuous mining machine for narrow platinum reefs, The Journal of The South African Institute of Mining and Metallurgy, Vol. 102, No. 1, 19-23

[6] Huang, M.; Li, G.; Wu, M.; An, W. (2003). Vibration measurement and modal analysis of boom type tunneller, Mining Technology, Vol. 112, No. 1, 69-72, doi:10.1179/037178403225011123

[7] Goktan, R. M. (1990). Effect of cutter pick rake angle on the failure pattern of high-strength rocks, Mining Science and Technology, Vol. 11, No. 3, 281-285, doi: $\underline{10.1016 / 0167-}$ 9031(90)90981-W

[8] Eyyuboglu, E. M.; Bolukbasi, N. (2005). Effects of circumferential pick spacing on boom type roadheader cutting head performance, Tunnelling and Underground Space Technology, Vol. 20, No. 5, 418-425, doi:10.1016/j.tust.2005.02.002

[9] Hekimoglu, O. Z.; Fowell, R. J. (1991). Theoretical and practical aspects of circumferential pick spacing on boom tunnelling machine cutting heads, Mining Science and Technology, Vol. 13, No. 3, 257-270, doi:10.1016/0167-9031(91)90397-U 
[10] Hekimoglu, O. Z. (1995). The radial line concept for cutting head pick lacing arrangements, International Journal of Rock Mechanics and Mining Sciences \& Geomechanics Abstracts, Vol. 32, No. 4, 301-311, doi:10.1016/0148-9062(95)00003-Y

[11] Hekimoglu, O. Z.; Ozdemir,L. (2004). Effect of angle of wrap on cutting performance of drum shearers and continuous miners, Mining Technology, Vol. 113, No. 2, 118-122, doi:10.1179/ $\underline{037178404225004977}$

[12] Yang, L.; Zhou, Z.-B. (2008). Study on pick arrangement on cutting head of roadheader, Coal Mine Machinery, Vol. 29, No. 12, 71-73 (in Chinese), doi:10.3969/j.issn.1003-0794.2008.12.031

[13] Li, X. H.; Lv, M.; Shi, X. B.; Do, T. H. (2010). Comparing and research on performance of two cutting heads with different kinds of pick arrangement, Journal of Liaoning Technical University (Natural Science Ed.), Vol. 29, No. 1, 136-138 (in Chinese)

[14] Wang, X.; Zhang, J.-Y. (2011). Spiral design of longitudinal roadheader cutting head, Coal Mine Machinery, Vol. 32, No. 9, 6-8 (in Chinese), doi:10.3969/j.issn.1003-0794.2011.09.003

[15] Yang, G.-D.; Gao, C.-Z.; Zhou, K.-M. (2011). Research of roadheader longitudinal design parameters of cutting head, Coal Mine Machinery, Vol. 32, No. 6, 46-48 (in Chinese)

[16] Zhang, M.-Q. (2013). Influence of pick array circumferential angle on cutting performance of longitudinal cutting head, Colliery Mechanical \& Electrical Technology, Vol. 22, No. 2, 19-23 (in Chinese), doi:10.3969/j.issn.1001-0874.2013.02.007

[17] Syddell, M. (2002). New roadheader idea for hard rock mining, Australian Mining, Vol. 94, No. 6,35

[18] Tiryaki, B.; Ayhan, M.; Hekimoglu, O. Z. (2001). A new computer program for cutting head design of roadheaders and drum shearers, Proceedings of the $17^{\text {th }}$ International Mining Congress and Exhibition of Turkey, Ankara, 655-662

[19] Rojek, J.; Onate, E.; Labra, C.; Kargl, H. (2011). Discrete element simulation of rock cutting, International Journal of Rock Mechanics and Mining Sciences, Vol. 48, No. 6, 996-1010, doi: $10.1016 /$ j.ijrmms.2011.06.003

[20] Su, O.; Akcin, N. A. (2011). Numerical simulation of rock cutting using the discrete element method, International Journal of Rock Mechanics and Mining Sciences, Vol. 48, No. 3, 434-442, doi:10.1016/j.ijrmms.2010.08.012

[21] Yang, F.; Chen, C.; Zhang, K.; Guo, C.-J.; Xu, J.-D. (2009). Broadband elliptical helical antennas with parasitic helix wire and variable pitch angle, High Power Laser and Particle Beams, Vol. 21, No. 5, 729-732 (in Chinese)

[22] Fu, S.-Q.; Zhou, Y.; Fang, S.-J.; Cao, Y. (2013). Design of low profile and variable pitch angle helical antenna for maritime satellite communications, Chinese Journal of Radio Science, Vol. 28, No. 1, 63-67 (in Chinese), doi:10.13443/j.cjors.2013.01.028

[23] Pei, Z.-J. (2007). On blade spiral line of mixing drum for truck concrete mixing, Construction Machinery, Vol. 9, No. 5, 54-55 (in Chinese)

[24] Rånman, K. E. (1985). A model describing rock cutting with conical picks, Rock Mechanics and Rock Engineering, Vol. 18, No. 2, 131-140, doi:10.1007/BF01019602

[25] Evans, I. (1984). A theory of the cutting force for point-attack picks, International Journal of Mining Engineering, Vol. 2, No. 1, 63-71, doi:10.1007/BF00880858

[26] Bilgin, N.; Demircin, M. A.; Copur, H.; Balci, C.; Tuncdemir, H.; Akcin, N. (2006). Dominant rock properties affecting the performance of conical picks and the comparison of some experimental and theoretical results, International Journal of Rock Mechanics and Mining Sciences, Vol. 43, No. 1, 139-156, doi:10.1016/j.ijrmms.2005.04.009

[27] Li, X. H. (2008). The Key Technology Research of the Roadheader Cutting, $1^{\text {st }}$ edition, Mechanical Industry Press, Beijing (in Chinese)

[28] Li, X.-Y.; Huang, B.-B.; Li, C.-C.; Jiang, S.-B. (2012). Dynamics analysis on roadheader cutting head based on LS-DYNA, Journal of Convergence Information Technology, Vol. 7, No. 23, 333340, doi:10.4156/jcit.vol7.issue23.39 